\title{
Análise do controle de itens de um almoxarifado: um estudo de caso na agência de Medianeira da Copel Distribuição S/A
}

\author{
Luani Back Silvina ${ }^{1}$ \\ Adriano Baroso ${ }^{2}$ \\ Suelem Alves de Andrade ${ }^{3}$
}

\begin{abstract}
Resumo: Este trabalho objetiva apresentar oportunidades de melhoria para o controle dos itens utilizados no atendimento às solicitações de serviços pela Copel Distribuição S/A. A metodologia utilizada foi baseada nas pesquisas descritivas e explicativas de natureza aplicada, com características tanto quantitativas quanto exploratórias. A fundamentação teórica está apoiada na pesquisa bibliográfica e os dados foram coletados por meio de questionário aplicado na amostra, que inclui os funcionários que trabalham com o almoxarifado da agência. A pesquisa permitiu identificar deficiências nos sistemas, quanto ao controle de entrada e saída de materiais e que acabam por permitir que os usuários informem dados incorretos. Para que a empresa funcione perfeitamente, os seus processos devem funcionar otimamente também e a melhor forma de garantir isso é aperfeiçoar os sistemas já existentes com mecanismos que evitem as falhas e as confusões no momento das inserções dos dados pelos usuários.

Palavras-chave: Materiais; Otimização; Almoxarifado.
\end{abstract}

\section{Analuysis from the control de items in a warehouse: a case study at the Copel Distribution S /A Agency in Medianeira}

\begin{abstract}
This study intentions is to present improvement opportunities for the control of the items used in the attendance of service requests by the Copel Distribution S/A. The methodology used in this project was based on the descriptive and explicative researches of applied nature, with both quantitative and qualitative characteristics. The theoretical foundation is supported by the bibliographical research, and the data were collected through a questionnaire applied in the sample, which includes the employees who work with the warehouse of the Copel agency. The research allowed to identify deficiencies in the systems, in terms of the control the inputs and outputs of the materials and that end up allowing users to report incorrect data. In order for the company to function perfectly, its processes should work optimally as well and the best way to ensure this is to improve the existing systems with mechanisms that prevent failures and confusion at the time of data insertion by users.
\end{abstract}

Keywords: Global leadership. Cultural diversity. Internationalization.

\footnotetext{
${ }^{1}$ Doutorado em andamento em Engenharia de Produção, pela Universidade Tecnológica Federal do Paraná, Campus Ponta Grossa. Mestre em Engenharia de Produção - Stricto Sensu, pela Universidade Tecnológica Federal do Paraná (UTFPR), Campus Ponta Grossa, na área de concentração de Gestão Industrial e linha de pesquisa Transferência de Tecnologia. Bacharel em Engenharia de Produção pela Universidade Tecnológica Federal do Paraná (UTFPR), Campus Medianeira.

${ }^{2}$ Graduado em Administração pela União Dinâmica de Faculdades Cataratas (UDC).

${ }^{3}$ Graduada em Administração pela União Dinâmica de Faculdades Cataratas (UDC).
} 


\title{
Análisis del control de ítems de un almacén: un estudio de caso en la agencia de Medianera de Copel Distribución S / A
}

\begin{abstract}
Resumen: Este estudio objetiva presentar oportunidades de mejora para el control de los elementos utilizados en la atención a las solicitudes de servicios por Copel Distribución S/A. La metodología utilizada se basó en las investigaciones descriptivas y explicativas de naturaleza aplicada, con características tanto cuantitativas como exploratorias. La fundamentación teórica se apoya en la investigación bibliográfica y los datos fueron recolectados por medio de un cuestionario aplicado en la muestra, que incluye a los funcionarios que trabajan con el almacén de la agencia. La investigación permitió identificar deficiencias en los sistemas, en cuanto al control de entrada y salida de materiales y que acaban por permitir que los usuarios informen datos incorrectos. Para que la empresa funcione perfectamente, sus procesos deben funcionar óptimamente también y la mejor manera de garantizar esto es perfeccionar los sistemas ya existentes con mecanismos que eviten las fallas y las confusiones en el momento de las inserciones de los datos por los usuarios.
\end{abstract}

Palabras clave: Materiales; Optimización; Almacén.

\section{Introdução}

A eterna busca pela perfeição gera a mudança constante e a competitividade exige a reinvenção, o novo e o eficiente. Tais situações surgiram com a globalização e elas são o reflexo das organizações atuais, que devem estar em constante mudança para almejar sempre o melhor, tanto para si quanto para o meio em que estão inseridas.

Saber administrar a disponibilidade de recursos e adequar os gastos com materiais auxilia no aperfeiçoamento dos processos da organização, além de afetar diretamente o fluxo de caixa das empresas. A gestão de estoques em grandes organizações é imprescindível para a obtenção de vantagem competitiva, pois os recursos materiais bem administrados garantem a continuidade das operações, o atendimento às demandas constantes e a possibilidade de redução de custos de forma planejada.

A Companhia Paranaense de Energia - Copel é uma empresa de economia mista, em que o maior acionista é o governo do Paraná e, por isso, faz-se necessário que a sua administração seja idônea e transparente. E as técnicas utilizadas no controle de materiais empregados na prestação de serviços pela Copel Distribuição S/A, subsidiária da Copel na qualidade de holding, são de grande importância para alcançar tais níveis de integridade.

A empresa demanda grande quantidade de itens para poder prestar serviço aos seus consumidores e esses materiais são utilizados por vários empregados que fazem parte do quadro de funcionários da organização. Sendo assim, faz-se necessário o acompanhamento e a correta aplicação desses itens, para, assim, evitar desperdícios e possíveis desvios. 
Este estudo tem como objetivo propor sugestões a fim de otimizar os resultados quanto ao sistema de controle de itens no almoxarifado na agência de Medianeira - PR da Copel Distribuição S/A.

\section{Fundamentação Teórica}

Viana (2006, p. 41) define a administração de materiais como o "planejamento, coordenação, direção e controle de todas as atividades ligadas à aquisição de materiais para a formação de estoques, desde o momento de sua concepção até seu consumo final”. Em complemento, Chiavenato (2005) assegura que os materiais devem ser controlados e administrados, pois a sua falta causará paradas na produção e o seu excesso elevará os custos operacionais de forma desnecessária, consequentemente, eles devem ser disponibilizados na quantidade, no momento e no local correto.

Segundo Arnold (1999), a administração de materiais possui, como objetivo, a maximização quanto à utilização de recursos da organização e o fornecimento de nível adequado conforme solicitado pelo consumidor. Sendo os recursos da empresa utilizados corretamente, o controle de materiais pode reduzir custo quanto à produção.

Dessa forma, os principais desafios da administração de materiais são: disponibilizar materiais para a atividade empresarial, com recuperação imediata e fácil entrega, através da utilização da logística de distribuição para oferecer esses itens no momento certo, com o menor prazo possível e com qualidade e custo baixo (CHIAVENATO, 2005).

Existem os estoques para fomentar o fluxo de materiais e auxiliar para que o processo produtivo não pare. Os estoques são de grande importância para as organizações, pois estão ligados diretamente aos investimentos realizados pela empresa e são ativos com baixa liquidez. "Entende-se por estoque quaisquer quantidades de bens físicos que sejam conservados de forma improdutiva, por algum intervalo de tempo" (MOREIRA, 2013, p. 447).

Segundo Slack, Chambers e Johnston (2009), estoques são necessários para abastecer a produção e entregar produtos e serviços aos clientes, mas, ao mesmo tempo, representam riscos, pois ao manter grandes volumes de produtos em estoque, existe o 
perigo destes perderem-se, deteriorarem-se ou tornarem-se obsoletos, além de gerar despesa financeira para compra e manutenção deles. Por isso, a importância de um gerenciamento eficiente para os suprimentos utilizados em todas as empresas.

A formação de estoques permanentes ocorre devido à necessidade de continuidade operacional, dificuldade em prever demanda futura, disponibilidade de entrega e cumprimento de prazos pelos fornecedores, estes últimos devem fazer parte de uma cadeia de fornecedores bem desenvolvida para o preciso fornecimento de materiais (KANNAN et al., 2013). Esses fatos são as principais causas que originam estoques volumosos e requerem investimentos e gastos proeminentes, mas garantem segurança para a operação de produção da organização (VIANA, 2006).

As perdas em uma organização representam pontos de extrema importância, uma vez que há um aumento significativo da diversidade de produtos com reduzido ciclo de vida e altos custos associados que exigem o aprimoramento da gestão de estoques e redução dos conflitos que existem entre as políticas de redução de perdas e a conservação do nível de serviço (SOUSA et al., 2016).

O correto gerenciamento de um estoque deve preencher alguns requisitos básicos, segundo Dias (2009), que são indiferentes ao tipo ou tamanho da organização:

a) todos os setores envolvidos como compra, recebimento, estocagem e pagamento de fornecedores, devem trabalhar conjuntamente e coordenadamente;

b) a existência de responsável pelas compras, que devem ser centralizadas;

c) cotação de preço dos fornecedores;

d) emissão de relatórios e conferência interna das compras e bens consumidos;

e) definição prévia de local para estocagem dos recursos;

f) inventário rotativo, em que seja possível determinar valor e quantidade dos materiais em estoque;

g) determinação de mínimo e máximo para o limite dos estoques.

De acordo com Ballou (2006), o gerenciamento de estoques está associado a diversos problemas, como os relacionados à natureza da demanda e aos pertencentes à forma da produção, se é puxada ou empurrada em relação aos estoques. No que concerne à demanda, Viana (2006) define que as previsões na gestão de estoque servem para diminuir as incertezas quanto à produção e essas previsões devem basear-se nas demandas, que podem ser de três tipos:

a) demanda perfeitamente conhecida: demandas constantes e regulares; 
b) demanda aleatória: comportamento irregular com relação ao tempo;

c) demanda sob incerteza: ignora os níveis de demanda futura.

Uma das funções da administração de materiais é a precisão nos registros de estoques, assim sendo, toda movimentação de materiais no estoque deve ser registrada em documentos ou sistemas adequados. Neste contexto, o almoxarifado ou depósito tem grande importância para a empresa, pois ele tem a função de controlar o efetivo de todo o estoque (DIAS, 2009).

Viana (2006) conceitua inventário físico como uma contagem periódica dos materiais existentes para a comparação com os estoques registrados e contabilizados em controle da empresa. Além disso, o mesmo autor afirma que todo sistema de controle de estoques está sujeito a falhas, logo o inventário é uma ferramenta de controle muito importante para o bom gerenciamento de qualquer empresa, visto que, com a sua realização, é possível detectar falhas no processo ou sistema e, assim, buscar a correção destas.

\section{Método}

$\mathrm{Na}$ busca pela identificação de oportunidades de melhoria para o controle dos itens utilizados no atendimento às solicitações de serviços pela Copel Distribuição S/A, este estudo fez uso da pesquisa de natureza aplicada, com características de pesquisa descritiva e explicativa. A base desta pesquisa é bibliográfica, documental e faz uso de conhecimentos obtidos através de aplicação de questionário junto aos colaboradores do setor em estudo e entrevista informal, para obtenção de informações pertinentes aos processos desenvolvidos.

A amostra abrangeu funcionários que trabalham diretamente com o almoxarifado da Copel Distribuição S/A, agência de Medianeira, sendo eles dois colaboradores do setor administrativo e trinta e dois eletricistas, que estão envolvidos diariamente com o controle, distribuição e a utilização dos materiais para prestação de serviços.

A fase de observação realizou-se na agência da Copel Distribuição S/A em Medianeira, assim como a entrevista informal com os colaboradores do setor administrativo, sendo que os questionários foram aplicados para os eletricistas, que atuam tanto nesta cidade como também nas cidades de São Miguel do Iguaçu, Matelândia, Céu 
Azul, Vera Cruz do Oeste, Santa Helena, Diamante do Oeste, Itaipulândia e Missal, que são de responsabilidade da agência em estudo.

\section{Discussão e resultados}

O processo para atender os clientes da Copel Distribuição necessita de uma grande quantidade de materiais que devem ser aplicados na rede de distribuição de energia, como também nas entradas de energia dos clientes, que são o conjunto de instalações composto pela caixa de medição, sistema de aterramento, condutores e poste. As entradas de energia são a conexão entre a rede da Copel e a casa do consumidor, empresa ou indústria.

Os materiais que são utilizados para a execução de serviços incluem itens como conectores, medidores, ramais, elos fusíveis e muitos outros objetos que devem ser comprados pela empresa por meio de licitação, com previsão de demanda, prazo para entrega e que ficam armazenados no almoxarifado central em Curitiba, nomeado de Atuba. Esse depósito alimenta os demais que estão distribuídos pelo estado do Paraná, localizados em Ponta Grossa, Maringá, Londrina, Cascavel e Curitiba, sendo este responsável por atender a capital.

Cada um desses almoxarifados intermediários alimenta os que estão próximos, como o de Cascavel, que é responsável pelo fornecimento de materiais para Toledo, Foz do Iguaçu, Francisco Beltrão, Pato Branco, como também para a própria cidade de Cascavel.

A agência de Medianeira, na questão relacionada a materiais, é subordinada ao centro de distribuição de Foz do Iguaçu e esse depósito é responsável por fornecer os produtos necessários para que a agência possa executar os seus serviços diariamente.

A maioria dos serviços executados na organização necessita da aplicação de materiais e forma estoques que devem ser acompanhados continuamente, pois, para a sua formação, é necessário que a empresa invista constantemente na compra de produtos para manter o propósito de um depósito, que é fornecer os materiais necessários para a execução das atividades diárias de uma organização. 
A coordenação do almoxarifado da agência de Medianeira é de responsabilidade de um funcionário de nível médio do setor administrativo, sendo que ele verifica os estoques de materiais, controla as entradas e saídas dos itens, como também procede ao inventário físico realizado quatro vezes por ano. Em relação ao gerenciamento, o funcionário faz o acompanhamento das saídas de materiais, utilizando o programa Sistema de Operação da Distribuição - SOD, que é o software encarregado de fazer a ligação entre os serviços gerados pelo atendimento e os dados que são inseridos pelos eletricistas em campo, via equipamento de comunicação móvel, após a equipe atender à solicitação do cliente.

No sistema SOD, é possível identificar os materiais que foram utilizados pelos veículos da agência e confrontar com a lista pré-determinada de itens que cada veículo deve possuir. A divergência entre essas duas listas permite que o responsável pelo depósito forneça para a equipe os materiais que estão faltando.

Para que a empresa trabalhe de forma otimizada, os materiais devem ser fornecidos quando da precisão da equipe em campo e é imprescindível evitar que muitos itens fiquem parados em posições do almoxarifado, aguardando para serem utilizados. Como o valor investido nesses produtos é alto, eles devem estar em constante movimentação através dos processos da organização, com a definição do menor estoque de segurança possível.

O controle da movimentação dos materiais deve ser executado a fim de evitar perdas para a organização. Os itens chegam à agência de Medianeira pelo almoxarifado de origem intermediário, situado em Foz do Iguaçu, e, no momento do recebimento, o responsável pelo almoxarifado de destino em Medianeira realiza a averiguação dos itens.

$\mathrm{Na}$ etapa de conferência, verifica-se a quantidade e o tipo dos materiais e, após, realiza-se a verificação deles com os pedidos emitidos. Caso a transferência esteja de acordo, o documento de aceite é repassado para outro funcionário administrativo, que realiza o aceite do documento através do sistema ERP/SAP. Transferem-se, assim, virtualmente, aqueles produtos para o depósito da agência e, após o recebimento, os materiais são armazenados em local com entrada restrita.

A agência de Medianeira possui, em sua frota, 15 veículos próprios e sete veículos pertencentes a empreiteiras que prestam serviço para a empresa. Todos esses veículos possuem materiais em estoque reduzido para atendimento das solicitações de serviços. Através da extração de um relatório, é feita a identificação e separação do que deve ser reposto paras as equipes. A fim de que os materiais saiam do depósito da agência, é necessário efetuar a transferência, através do sistema ERP/SAP, dos itens para a posição 
desejada. Com a transição realizada, os materiais são entregues para as equipes e estas estocam os itens nos veículos, segundo princípios do programa $5 \mathrm{~S}$.

O fornecimento de materiais fisicamente representa despesa significativa para a quase todos os negócios e afeta diretamente a competitividade quando relacionada à velocidade, confiabilidade e capacidade de rastreamento dos processos (MARTINS; ALT, 2009).

A movimentação dos estoques na empresa acontece com a execução de serviços em campo, que consomem grande quantidade de material diariamente. Cada equipe possui um tablet, que é utilizado para comunicação entre os funcionários e auxilia no posicionamento das equipes em relação às configurações das redes elétricas. Esses equipamentos também recebem diariamente os serviços que as equipes deverão executar. Cada serviço possui um número de protocolo atrelado a ele, que está vinculado ao cliente que o solicitou e é denominado Solicitação de Serviço - SS.

Os itens que são aplicados em campo são retirados da posição do veículo que está relacionado no tablet da equipe. Ressalta-se que esse processo é realizado várias vezes ao dia, conforme a equipe executa os serviços que foram programados pelo controlador da agência. No entanto, a conferência do estoque do veículo não é feita no momento da conclusão do serviço, sendo assim, o funcionário pode informar qualquer material que deseja para finalizar a SS, mesmo que não possua esse item, tanto físico quanto contabilmente.

Constataram-se, durante a pesquisa, vários problemas relacionados aos sistemas que são utilizados na empresa para o controle dos estoques de materiais. No caso do sistema ERP/SAP, que é utilizado na solicitação de pedidos de materiais e nas transferências deles para as posições dos veículos, verificou-se que funcionários que possuem acesso às transações de almoxarifado podem efetuar alterações tanto no depósito de sua agência como também nos demais depósitos da empresa. Tal situação diminui a credibilidade do sistema, pois mesmo que a agência em questão consiga controlar o seu fluxo de materiais, ela não tem a garantia de que outra área não irá alterá-lo por engano ou mesmo de propósito.

Para poder executar a função de eletricista, os funcionários terceirizados devem ser capacitados com treinamentos específicos para a atuação na rede de distribuição de energia, mas recebem pouco treinamento em relação à utilização dos equipamentos móveis 
de comunicação e dos aplicativos que são utilizados diariamente para a inclusão de informações nos sistemas da empresa.

O questionário expôs a falha dos equipamentos eletrônicos e do aplicativo SOD Móvel, pois, apesar da grande quantidade de materiais e a similaridade entre eles, no momento da sua aplicação em campo é muito difícil confundi-los. Mas, no momento da conclusão do serviço no tablet, tal falha torna-se possível, uma vez que o SOD Móvel não está preparado para evitar erros. O programa não verifica, no momento da conclusão do serviço, se o veículo em questão possui realmente os materiais que está informando na finalização da SS.

Em conversa com as equipes, foi possível identificar problemas constantes em relação aos equipamentos móveis, pois estes travam várias vezes durante o período de trabalho e é necessário reiniciar os equipamentos para poder retornar ao serviço em execução. Esses aparelhos são levados ao extremo, pois são utilizados por várias horas seguidas e durante o mau tempo, quando as equipes têm de atender aos chamados de falta de energia.

A empresa buscou alternativa para esses aparelhos, mas os novos equipamentos, apesar de serem mais robustos e possuírem conexão via satélite, não foram aceitos pelos empregados, uma vez que travavam mais que os tablets e também eram mais lentos. Com esses dispositivos, as equipes perdiam muito tempo para concluir os serviços e, por vezes, não conseguiam finalizar as solicitações de serviços.

Normalmente, as falhas não são de responsabilidade de um único elo da corrente e, no caso do fornecimento e utilização de materiais pela Copel Distribuição, é possível verificar que os problemas estão em toda a cadeia, desde a previsão da demanda, realização das compras, distribuição dos materiais e até a utilização dos itens no processo final.

Observou-se, através desta pesquisa, que os itens que necessitam maior atenção e são atitudes viáveis para a empresa melhorar são: a aplicação de treinamento relacionado aos materiais e programas para os eletricistas que fazem a conclusão das solicitações de serviços e uma melhoria nos aplicativos utilizados pelas equipes para impedir falhas humanas.

Com relação à mão de obra, nota-se que a maioria das dificuldades refere-se ao uso dos sistemas e, como consequências, constatou-se que o grande número de irregularidades do inventário da empresa acontece com funcionários que não tiveram um 
treinamento próprio para usar o aplicativo da empresa. Após essa constatação, é possível definir que um programa de treinamento para esses colaboradores poderia reduzir os problemas enfrentados pela empresa.

A empresa treina os seus funcionários próprios durante muito tempo, tanto com treinamentos relacionados aos serviços que serão prestados na empresa, como também tem a política de deixar o novo empregado sob supervisão de um funcionário mais antigo. Dessa forma, além de ser feito o acompanhamento em relação à segurança do trabalhador, este pode adquirir conhecimentos internos e, como consequência, aprender a utilizar as ferramentas tecnológicas que são disponibilizadas pela empresa.

Em relação aos funcionários terceirizados, a Copel Distribuição considera que eles já foram treinados e espera que, assim que forem liberados os contratos, as equipes estejam aptas para começar a trabalhar normalmente. Todavia, esses empregados novos não têm como saber a forma correta de utilizar os softwares da organização e não recebem treinamento e acompanhamento adequado. Dessa forma, é de grande importância que a empresa desenvolva um programa de treinamento direcionado especialmente para os funcionários terceirizados.

Além do treinamento, a Copel Distribuição deveria solicitar que as empresas terceirizadas exigem, no mínimo, o ensino médio completo de seus funcionários, para, assim, garantir que os empregados estivessem aptos a utilizar as ferramentas disponíveis. Para fazer parte do quadro de funcionários próprios da organização, é preciso prestar concurso público de nível médio, o que acaba por selecionar funcionários. A empresa treina os seus empregados constantemente, preocupada sempre em melhorar a sua força de trabalho. Mas fica visível que o mesmo não ocorre com as suas equipes terceirizadas, que, para os consumidores, representa a empresa da mesma forma que um funcionário concursado.

Uma vez que a equipe está preparada para utilizar as ferramentas que lhe são destinadas, certamente conseguirá produzir com maior efetividade. De nada adianta grandes investimentos em tecnologias e controles se, uma das partes do sistema está despreparada e não possui entendimento da real necessidade de executar corretamente os seus procedimentos, pois tais falhas geram problemas maiores.

O sistema atual usado na empresa para a conclusão de serviços possui algumas adversidades quanto ao seu uso, uma questão de grande importância e que praticamente todos os colaboradores relataram foram as quedas do sistema e travamentos dele. Isso 
atrapalha o andamento dos serviços, além de prejudicar o controle eficaz dos estoques que os eletricistas possuem em seus veículos. Para tal problema, o correto seria adquirir equipamentos de informática que fossem preparados para as intempéries que as equipes enfrentam diariamente. Mas aparelhos com configurações avançadas possuem valor de mercado superior e, muitas vezes, a empresa prefere não efetuar investimentos maiores para garantir resultados melhores.

Outro fator que prejudica a qualidade do aplicativo SOD Móvel, é que ele permite que o funcionário, em campo, faça a aplicação de um item que não se encontra no estoque do seu veículo, isso acaba por gerar a falta de um material e o saldo incorreto de outro. Tal situação poderia ser corrigida com a implementação de uma atualização nos aplicativos, assim, antes da efetivação da conclusão da SS, seria feita a confrontação instantânea dos materiais utilizados com os disponíveis no veículo.

Verificou-se que os erros não acontecem somente com as equipes em campo, mas também durante a movimentação, via sistema dos materiais entre os almoxarifados, pelos funcionários responsáveis, uma vez que qualquer funcionário que possua perfil para executar as transações de almoxarifado pode acessar qualquer depósito da empresa e efetuar alguma alteração por falta de atenção ou mesmo de forma proposital.

O software utilizado para essas transações é o ERP/SAP, que foi adquirido pela empresa em 2011, mas é de suma importância que a organização solicite à empresa responsável a implementação de bloqueios conforme a área de atuação dos funcionários para, assim, evitar que este interfira em depósitos que não são de sua responsabilidade.

Vários problemas foram identificados e algumas soluções foram sugeridas, conforme é possível verificar na sequência:

a) aplicação de treinamento para os eletricistas, referente à utilização do software SOD Móvel e procedimentos relacionados ao almoxarifado;

b) inclusão nos contratos de licitação das novas empreiteiras a necessidade de apresentar funcionários com, no mínimo, ensino médio completo;

c) aquisição de novos dispositivos móveis com especificações próprias para as características das atividades prestadas pelos eletricistas;

d) implementação de melhorias no aplicativo SOD Móvel, que visem à prevenção de prováveis falhas por parte dos usuários, como também a conferência online do estoque relacionado à posição dos veículos no momento da conclusão dos serviços; 
e) solicitação de ordem de melhoria aos responsáveis pelo programa ERP/SAP, para que implementem upgrades em relação à permissão de acesso aos almoxarifados de cada agência.

No entanto, somente alterar esses procedimentos não garantirá a extinção das falhas, toda a equipe deve estar ciente dos problemas e conhecer as possíveis soluções para que seja possível ajudar a organização a alcançar as metas estabelecidas.

\section{Considerações Finais}

Ao determinar a importância de uma otimização no controle de estoques, tanto na questão financeira, como também na eficiência de toda a operação, geram-se, assim, ganhos em escala de cada parte da cadeia operacional e é o que justificou a conveniência de uma pesquisa neste tema.

Verificaram-se dois grandes fatores para que a gestão dos estoques não seja considerada eficiente dentro da organização, que são: 1) a falta de instrução da mão-deobra terceirizada; e 2) um sistema controle de itens que permite falhas desnecessárias. Além disso, vários outros fatores interferem, como no caso da similaridade dos materiais e as características da atividade de eletricista, que é feita em condições muitas vezes não favoráveis. Tais problemas também interferem no fluxo dos materiais dentro da organização, mas os dois fatores expostos anteriormente são o que mais ocasionam erro e que podem ser resolvidos.

Foram sugeridas algumas alternativas que podem ser empregadas pela empresa por serem viáveis e oportunas neste momento de transição e que, possivelmente, podem resolver esse problema importante. Afinal, caso a empresa continue com a forma atual de gestão de seus estoques, os problemas continuarão a existir.

Com um bom processo de controle de estoques, custos desnecessários com compra de material ou a falta de material, além de retrabalhos para conferência e fechamento de inventário podem ser reduzidos, isso acaba por gerar um aumento da eficiência operacional e, como consequência, um aumento na lucratividade da organização.

\section{Refêrencias}


ARNOLD, J. R. Tony. Administração de materiais: uma introdução. São Paulo: Atlas, 1999.

BALLOU, Ronald H. Gerenciamento da cadeia de suprimentos: logística empresarial. 5. ed. Porto Alegre: Bookman, 2006.

CHIAVENATO, Idalberto. Administração de materiais: uma abordagem introdutória. 3. ed. Rio de Janeiro: Elsevier, 2005.

COPEL. Copel. 2017. Disponível em: http://www.copel.com.br/. Acesso em: 10 fev 2017. DIAS, Marco Aurélio. Administração de materiais: princípios, conceitos e gestão. 6. ed. São Paulo: Atlas, 2009.

KANNAN, G; GRIGORE, M. C.; DEVIKA, K.; SENTHIKUMAR, A. An Analysis of the general benefits of a centralised VMI system based on the EOQ model. International Journal of Production Research, v. 51, n. 1, p. 172-188, 2013.

MARTINS, Petronio Garcia; ALT, Paulo Renato. Administração de materiais e recursos patrimoniais. 3. ed. São Paulo: saraiva 2009.

MOREIRA, Daniel Augusto. Administração da produção e operações. 2. ed. São Paulo: Cengage Learning, 2013.

SLACK, Nigel; CHAMBERS, Stuart; JOHNSTON, Robert. Administração da produção. 3. ed. São Paulo: Atlas, 2009.

SOUSA, Paulo R.; SILVA, Rosnaldo I.; BRAGA, Bruna C. A utilização de VMI para gestão de estoques na indústria calçadista brasileira: desenvolvimento de um modelo. GEPROS, Gestão da Produção, Operações e Sistemas, ano 12, nº 1, jan-mar/2017, p. 123$140,2016$.

VIANA, João José. Administração de materiais: um enfoque prático. 1. ed. São Paulo: Atlas, 2006. 